\title{
Rapid evaluation of different Perovskite absorber layers through the application of depth profile analysis using Glow Discharge - Time of Flight Mass Spectrometry
}

\author{
Beatriz Fernandez, ${ }^{* 1}$ Lara Lobo, ${ }^{1}$ PriyankaTyagi, ${ }^{2}$ Vasil Stoichkov, ${ }^{2}$ \\ Jeff Kettle ${ }^{2}$ and Rosario Pereiro ${ }^{1}$
}

${ }^{1}$ Department of Physical and Analytical Chemistry; Faculty of Chemistry; University of Oviedo; Julian Clavería, 8. 33006 Oviedo (Spain).

${ }^{2}$ School of Electronic Engineering, Bangor University, Dean Street, Bangor, Gwynedd, Wales, UK LL57 1UT (Wales, UK)

*Author to whom correspondence should be addressed

Corresponding author: fernandezbeatriz@uniovi.es

Telephone: +34.985 .103524$ 


\begin{abstract}
Depth profile analysis of perovskite absorber layers deposited onto glass substrates is investigated by radiofrequency pulsed glow discharge - time of flight mass spectrometry (rfPGD-ToFMS). Elemental depth profiles obtained for perovskite films fabricated using a double-step deposition route with different precursors (methylammonium iodide and $\mathrm{PbI}_{2}$, $\mathrm{PbCl}_{2}$ or $\mathrm{PbBr}_{2}$ ) show varying distribution of the principle components depending on the precursors employed. Furthermore, the results show that rf-PGD-ToFMS allows to identify traces of residue solvent used in the initial film preparation (dimethyl sulphoxide or dimethylformamide) and to identify differences produced by film thickness and oxygen uptake caused by exposure to ambient conditions. The approach also enables inspection of the differences in elemental diffusion and the degradation processes. By using rf-PGD-ToFMS, no ultra-high-vacuum is needed for processing and rapid analysis of absorber films can be obtained in less than $40 \mathrm{~s}$. The demonstration of such powerful analytical technique for obtaining depth profile information could enable groups in the field to better optimize processing conditions and enhance stability.
\end{abstract}

Keywords: Thin film solar cells; Perovskite solar cells; Depth profile analysis; Radiofrequency pulsed glow discharge; Time of flight mass spectrometry 


\section{INTRODUCTION}

Inorganic-organic hybrid compounds, with the crystal structure of a perovskite, have generated significant international interest for their application as light absorbers in solar cells, owing to their relatively easy fabrication process, small optical band-gaps, high extinction coefficients, and high carrier mobility [1,2]. Over the last decade, the power conversion efficiency of perovskite solar cells (PSCs) has been increased from $3.8 \%$ in 2009 [3] up to $21.2 \%$ in 2017 [4], generating significant commercial interest in the renewable energy community. The general formula for hybrid perovskites is $\mathrm{ABX}_{3}$, where A consists of an organic cation (e.g. methyl-ammonium, ethyl-ammonium, or formamidinium), B is a divalent metal cation of carbon family (i.e. $\mathrm{Pb}^{2+}, \mathrm{Sn}^{2+}, \mathrm{Ge}^{2+}$ ), and $\mathrm{X}$ is a monovalent halogen anion (i.e. $\mathrm{F}^{-}, \mathrm{Cl}^{-}, \mathrm{Br}^{-}, \mathrm{I}^{-}$) or a coexistence of several halogens. Selection of all the components ( $\mathrm{A}, \mathrm{B}$ and $\mathrm{X}$ ) is critical to the semiconducting and optical properties which consequentially impacts upon the photovoltaic performance [5]. For example, the optical absorption as well as photoluminescence of PSCs is directly related to the metal halide employed: the use of iodides results in smaller bandgap and light emission at longer wavelengths, whereas the use of bromides leads to higher bandgap and luminescence at shorter wavelengths [6].

Despite the promising performances of this type of photovoltaic devices, the poor stability of PSCs is one of the main obstacles needed to be overcome [7-9]. The chemical stability of PSCs is defined by a multitude of chemical reactions and physical changes of the perovskite films, electrodes or interlayers under different atmospheres and conditions. The absorber layer itself is susceptible to a several environmental factors including UV light, moisture, oxygen and elevated temperatures [10-13]. Therefore, to improve the stability of PSCs, systematic understanding of the degradation mechanisms and their effect on the device performance is still essential.

The stability studies of PSCs have been typically performed using current-voltage characteristics, UV-vis absorption measurements, SEM and X-ray diffraction (XRD) analysis. However, information related to elemental distribution, the presence of impurities and diffusion processes between the layers of the cell could also give valuable information. Indeed, ion migration during the operation of PSCs impacts upon solar cell performance and is likely to be one of the major factors that causes "reversible degradation" [14]. To study ion migration and impurity levels, several solid-state spectrometric techniques have been recently employed for depth profiling analysis of PSCs, including secondary ion mass spectrometry (SIMS), Rutherford backscattering spectrometry (RBS), particle induced X-ray emission (PIXE) and X-ray photoelectron spectroscopy (XPS) [15-19]. Elemental depth profiles of 
$\mathrm{MAPbI}_{3}$ films formed on mesoporous titanium oxide were reported using time of flight (ToF) SIMS [16]. Additionally, perovskite formed by a single-step and double-step deposition route (using $\mathrm{PbI}_{2}$ and $\mathrm{PbCl}_{2}+\mathrm{MAI}$ as precursors) have been investigated by ToF-SIMS imaging of the top surface. ToF-SIMS has provided many important conclusions, such as defects in the underlying layers were found to possibly induce cracks in the perovskite and allow the percolation of the evaporated metal from the top electrode [15]. Barreiros et al. [18] used PIXE and RBS for depth profiling of perovskite films and precursor materials present in the active layers, allowing to identify non-uniform surface coverage regions of the perovskite film as well as to establish the undesired presence of $\mathrm{PbI}_{2}$. On the other hand, XPS was used to investigate the compositional changes within perovskite layer caused by device degradation over the period of $1000 \mathrm{~h}$ in open air. XPS spectra confirm the penetration of In and Sn from indium tin oxide towards the top surface of $\mathrm{CH}_{3} \mathrm{NH}_{3} \mathrm{PbI}_{3}$ perovskite layer, that can be identified as the major reason for the instability of the cells [19].

Although SIMS, PIXE and XPS techniques offer excellent analytical performance for depth profile analysis of PSCs, they also possess significant drawbacks, such as matrix effects, the need of ultra-high-vacuum conditions and long-duration analysis. Glow discharge (GD) coupled to optical emission or mass spectrometry (OES and MS, respectively) provide an alternative method for fast direct analysis of layered samples with high depth resolution [20]. GD sources operate at moderate low-pressure conditions, significantly reducing costly and time-consuming ultra-high-vacuum requirements. Moreover, the low-energy $\mathrm{Ar}^{+}$ions used for the analysis ensure that sputtering proceeds without significant formation of altered layers (a critical prerequisite for a successful depth profile).

Concerning application of GD to PSCs analysis, few reports have been conducted to date (all of them using OES detection). The distribution of chlorine and iodine was investigated in $\mathrm{CH}_{3} \mathrm{NH}_{3} \mathrm{PbI}_{3-\mathrm{x}} \mathrm{Cl}_{\mathrm{x}}$ based PSCs using GD-OES operating in continuous mode [21,22]. Experimental results showed that $\mathrm{Cl}$ was distributed in the bulk of the perovskite film (i.e. it was not accumulated at the $\mathrm{TiO}_{2} / \mathrm{CH}_{3} \mathrm{NH}_{3} \mathrm{PbI}_{3}$ interface). Also, by applying a bias to the cell, migration of $\mathrm{Cl}$ and I through the device was observed and such migration can influence the electrical characteristics of PSCs. In the same way, the elemental distribution of In, C, O, N, $\mathrm{Ti}$ and $\mathrm{Sn}$ [19] as well as $\mathrm{Pb}$ and $\mathrm{S}$ [23] have been recently studied on PSCs. Elemental migration of In, Sn, Ti and S was reported as an important factor causing the electrical performance in solar cells to degrade.

Although MS detection offers higher sensitivity compared to OES, the most common analyzers used in GD-MS are sequential (i.e. sector field). However, the combination of a 
radiofrequency (rf) pulsed GD (PGD) coupled with a time of flight (ToF)-MS enables timegated detection of formed ions along the GD pulse period. In such way, it is possible to discriminate analytical signals at different time positions, allowing to achieve the highest analyte signal with minimum spectral interferences [24]. This is an important advantage as compared with non-synchronized detection [21,22]. Moreover, ToFMS allows fast and simultaneous full spectral acquisition. This possibility opens new opportunities in the data treatment step: it is possible to use stored spectra to search for unexpected elements in thin layers, to solve signal saturation using other regions of the pulse profile, or to use a low intense polyatomic ion (e.g. argide) of the analyte [25].

In this paper, the elemental depth profiles of PSCs, fabricated using a double-step deposition route with different precursors (methylammonium iodide and $\mathrm{PbI}_{2}, \mathrm{PbCl}_{2}$ or $\mathrm{PbBr}_{2}$ ), obtained byrf-PGDToFMS are reported. The use of $\mathrm{PbI}_{2}, \mathrm{PbCl}_{2}$ or $\mathrm{PbBr}_{2}$ shows advantages and limitations in the prepared absorber layers related to their absorption and stability and, therefore, depth profile analysis would allow understanding the different distribution of the perovskite's compositional components depending on the precursors employed. A careful selection of experimental conditions is performed taking into account challenging characteristics of the samples with organic layers on the top of a glass substrate. Furthermore, the distribution of $\mathrm{Pb}$ and halogens was investigated in detail at different times after the preparation of the perovskite films in order to identify diffusion related degradation processes in the layers, which can have a direct influence on the origin of hysteresis in PSCs.

\section{EXPERIMENTAL SECTION}

\subsection{Samples Preparation: Perovskite thin film}

Methylammonium iodide (MAI, code 14965-49-2), lead iodide ( $\mathrm{PbI}_{2}$, code 10101-63-0), lead bromide $\left(\mathrm{PbBr}_{2}\right.$, code 10031-22-8) and lead chloride $\left(\mathrm{PbCl}_{2}\right.$, code 7758-95-4) were purchased from Lumtec (Taiwan) with $99.999 \%$ purity. Dimethyl sulphoxide (DMSO, code 67-68-5), dimethylformamide (DMF, code 68-12-2) and isopropyl alcohol (IPA, code 67-630) were purchased from Sigma-Aldrich (UK).

Table 1 summarizes the different samples evaluated in this work. In all cases, a two-step sequential deposition method was used for preparation of perovskite films using a glass substrate $\left(1.1 \mathrm{~mm}\right.$ thick and $4 \mathrm{~cm}^{2}$ area). Glass substrates were cleaned by sequentially ultrasonicating in deionized water, acetone and isopropanol each for $20 \mathrm{~min}$ followed by oxygen plasma treatment for $5 \mathrm{~min}$. Three type of perovskite films $\left(\mathrm{MAPbI}_{3}, \mathrm{MAPbBr}_{2} \mathrm{I}\right.$ and 
$\mathrm{MAPbCl}_{2} \mathrm{I}$ ) were deposited by varying the halide component. Separate precursor solutions were prepared of MAI (30 mg) in $1 \mathrm{~mL}$ isopropanol, $\mathrm{PbI}_{2}(461 \mathrm{mg})$ in $1 \mathrm{~mL} \mathrm{DMF}, \mathrm{PbCl}_{2}(300$ $\mathrm{mg}$ ) in $1 \mathrm{~mL}$ DMSO and $\mathrm{PbBr}_{2}(367 \mathrm{mg})$ in $1 \mathrm{~mL} \mathrm{DMF}$. $\mathrm{PbI}_{2}$ and $\mathrm{PbB}_{2}$ solutions were filtered by using a $0.45 \mu$ PTFE filter. For $\mathrm{MAPbI}_{3}$ deposition, $\mathrm{PbI}_{2}$ solution was spin coated at 6000 rpm (method A for thin film) and $2000 \mathrm{rpm}$ (method B for thick film) for $40 \mathrm{~s}$ from a solution heated at $70{ }^{\circ} \mathrm{C}$ for $10 \mathrm{~min}$. Substrates were then annealed at $90{ }^{0} \mathrm{C}$ for $20 \mathrm{~min}$. Subsequently, MAI was deposited at $6000 \mathrm{rpm}$ for $40 \mathrm{~s}$ and films were annealed at $90{ }^{0} \mathrm{C}$ for $20 \mathrm{~min}$. Similarly, for $\mathrm{MAPbBr}_{2} \mathrm{I}$ and $\mathrm{MAPbCl}_{2} \mathrm{I}$, first $\mathrm{PbBr}_{2}$ and $\mathrm{PbCl}_{2}$ was deposited with the process similar to $\mathrm{MAPbI}_{3}$ followed by MAI deposition with same conditions. The thickness of the perovskite films was determined by profilometry (Bruker DektakXT) and found to be $\sim 300 \mathrm{~nm}$ (method "A") and $500 \mathrm{~nm}$ (method "B"). Measurements were performed on fresh and aged samples. For aging, each sample was exposed to 1 sun $\left(100 \mathrm{mWcm}^{2}\right)$ for $4 \mathrm{~h}$ under solar simulator (Newport model no. 94021A).

In order to prevent any immediate degradation process of the perovskite films, encapsulation of the samples was done after the deposition of perovskite films by sealing with a glass cover slip in the glovebox. The encapsulation was removed before the analysis by rfPGD-ToFMS.

\subsection{Instrumentation and Experimental Conditions for rf-PGD-ToFMS Analyses}

For this work, the instrument "PP-TOFMS Plasma Profiling Spectrometer" from Horiba Scientific (France) was used. The GD source is a $4 \mathrm{~mm}$ diameter copper-based anode (i.e. a 4 $\mathrm{mm}$ crater is produced in the sample surface) with a $20 \mathrm{~mm}$ long flow tube. The rf power is supplied to the plasma through the backside of the sample (placed horizontally). The interface of the system is formed by a $0.5 \mathrm{~mm}$ sampler followed by a $1 \mathrm{~mm}$ skimmer cone. A quadrupole (notch filter) is placed just after the extraction cone, allowing attenuation up to 4 isotopes at different masses to reduce detector overloading. Typically, the quadrupole filter is employed for major plasma gas species and/or matrix elements. Moreover, it is possible to select the amplitude for each isotope so that the signal attenuation can be modulated. In this study, ${ }^{40} \mathrm{Ar}^{+}$(0.3 amplitude) was attenuated. To obtain a complete depth profile of all the perovskite solar cells constituents and, therefore, a good sensitivity of all elements (e.g. N, C, $\mathrm{Pb}, \mathrm{Si}$, etc.), measurements were conducted in the positive detection mode. This was selected as a compromise for reasonable sensitivity of most of the sample constituents, which wouldn't have been possible in negative detection mode. High purity Ar was employed as discharge gas. Instrument calibration (including the baseline, mass calibration, sensitivity evaluation 
and amplitude factor for the signal attenuation) was daily performed before the analysis of the samples by measuring a high purity silicon wafer.

ToFMS extraction frequency was fixed at $30 \mathrm{kHz}$, so a full mass spectrum (up to $290 \mathrm{~m} / \mathrm{z}$ ) was obtained every $33 \mu \mathrm{s}$. The GD source was operated in the pulsed mode and experimental conditions (70 W rf forward power, $120 \mathrm{~Pa}$ Ar pressure, $200 \mu$ s pulse width, and $1400 \mu \mathrm{s}$ pulse period). These values were selected as a compromise between reasonable sensitivity for the analytes (particularly for those present in the perovskites absorber layers) and good depth resolution through the analysis of perovskite films deposited onto the glass substrate. Concerning depth resolution, it should be stated that in order to obtain good depth resolution, the crater shape of the sputtered material is of crucial importance; the flatter the bottom of the crater (with the crater walls perpendicular to the sample surface), the better the depth resolution. For all experiments, data shown with depth profiles correspond to averaged intensity signals (ion intensities) in the afterglow region of the GD pulse profile (region where maximum signals were obtained). However, it should be noted that the afterglow region selected for integration was not the same for all the isotopes (see Table 2). The integration region was optimized for each analyte in terms of sensitivity and absence of spectral interferences [24].

To achieve reliable depth profiling of thin layers using GDs, it is crucial to provide experimental conditions for a stable plasma at the beginning of the sputtering process. This is particularly important in the case of perovskite films due to the nature of the samples: nanometric layers of inorganic-organic hybrid compounds on the top of a non-conducting glass substrate. Importantly, an iodine memory effect was also observed (discussed in next section) and, therefore, an efficient method to reduce the iodine signal to a background level was developed. Briefly, the following procedure was used for perovskite films measurements by rf-PGD-ToFMS: (i) Since perovskite films tend to be very unstable, samples were kept in dark conditions inside desiccator after preparation and the glass cover used for encapsulation was removed just before rf-PGD-ToFMS analysis, (ii) To reduce the amount of gas species that can be occluded in the sample and chamber surfaces, a flushing step with Ar during 4 min was applied to the GD source and the sample surface, and (iii) High-purity silicon were sputtered in the GD source for $20 \mathrm{~min}$ after each perovskite film analysis to remove iodine signal retained in the system (such $\mathrm{Si}$ wafer sputtering can contribute also to create a $\mathrm{Si}$ coating on the source that could reduce water desorption). 


\section{RESULTS AND DISCUSSION}

\subsection{Optimization of analysis conditions for depth profiling of perovskite films.}

The "memory effect" is a well-known phenomenon in inductively coupled plasma (ICP) MS measurements of volatile elements, such as $\mathrm{Cd}, \mathrm{I}, \mathrm{Pb}, \mathrm{Li}$ and $\mathrm{Hg}$ [26]. However, to our knowledge, it was not reported previously for analysis performed by GD sources. Most PSCs have a high content of iodine and a significant memory effect was observed in rf-PGDToFMS analysis of perovskite absorber films. Figure 1 shows the depth profile of ${ }^{28} \mathrm{Si}^{+}$and ${ }^{127} \mathrm{I}^{+}$obtained for a high-purity $\mathrm{Si}$ wafer analyzed just after a perovskite film $\left(\mathrm{MAPbI}_{3}\right)$. As can be seen, a prominent signal for ${ }^{127} \mathrm{I}^{+}$is observed (especially in the first seconds of the analysis) although this element is unlikely to be present in the Si wafer. Such a memory effect can be attributed to the volatility of iodine, which leads to iodine adsorption at different retention sites, such as the GD anode, sampler and skimmer cones, etc. The slow wash-out time of ${ }^{127} \mathrm{I}^{+}$signal can be seen in the expanded graph for the first $5 \mathrm{~min}$ of the analysis (note that this graph is in logarithmic scale). It was found that it is possible to return ${ }^{127} \mathrm{I}^{+}$signal to background level after 15-20 min of Si sputtering. Thus, as described in the experimental section, after the analysis of a perovskite film, sputtering of a high-purity Si wafer was performed for $20 \mathrm{~min}$ to prevent any cross contamination of iodine between samples, which can be detrimental for PSCs analysis by rf-PGD-ToFMS. The iodine memory effect was not previously reported for the analysis of perovskite films using GD-OES. However, this can be attributed to the lower sensitivity exhibited by GD-OES compared to MS detection.

Figure 2 shows the qualitative depth profile (signals intensity versus sputtering time) obtained for $\mathrm{MAPbI}_{3}$ sample (method A) by rf-PGD-ToFMS using the optimized experimental conditions. In case of $\mathrm{MAPbI}_{3}$ samples, $\mathrm{PbI}_{2}$ is expected to be observed at the interface due to the two step deposition route used for perovskite film. This has been observed by X-ray diffraction analysis: unreacted $\mathrm{PbI}_{2}$ can be found even in the solar cells with efficiency over $15 \%$ [27]. As can be seen in the Figure, a complete depth profile of the sample, including the perovskite film and the glass substrate can be obtained in a relatively short time; in this case $20 \mathrm{~s}$ was required to obtain information of the coating layers $(\sim 300$ $\mathrm{nm})$. By using rf-PGD-ToFMS, a rapid analysis of the organic and inorganic components of the sample can be readily obtained: $\mathrm{Pb}, \mathrm{I}, \mathrm{C}$, and $\mathrm{N}$ were monitored to distinguish the coating layers, whereas $\mathrm{Si}, \mathrm{Mg}$, and $\mathrm{O}$ were selected for the glass substrate. It should be noticed that the $\mathrm{I}$ in the layers was not monitored using ${ }^{127} \mathrm{I}^{+}$isotope (100\% natural abundance) since saturation of the signal was observed ( $>1000 \mathrm{mV}$ signal in the mass spectrum). 
As previously demonstrated for the analysis of tandem solar cells by rf-PGD-ToFMS [25], polyatomic ions with Ar gas can be used for depth profiling of major components. Thus, ${ }^{127} \mathrm{I}^{40} \mathrm{Ar}^{+}$and ${ }^{79} \mathrm{Br}^{40} \mathrm{Ar}^{+}$(for $\mathrm{MAPbBr}_{2} \mathrm{I}$ samples) were used throughout the article to monitor I and $\mathrm{Br}$, respectively. As shown in Table 2, a time interval of $0.133 \mathrm{~ms}$ in the afterglow region of the GD pulse profile was selected in all cases for integration, except for ${ }^{32} \mathrm{~S}^{+}$where a smaller interval was chosen to avoid ${ }^{16} \mathrm{O}_{2}{ }^{+}$interference. Note that rf-PGD-ToFMS profiles show intensity signals for the elements that vary in a wide range (e.g. $\sim 200 \mathrm{~V}$ for ${ }^{204} \mathrm{~Pb}^{+}$ versus $8.6 \mathrm{~V}$ for ${ }^{127} \mathrm{I}^{40} \mathrm{Ar}^{+}$). However, these intensities do not correspond directly to the relative elemental concentrations due to changes in the sample sputtering rate, to different ionization yields for each element, and to the fact that in some cases the measurement of polyatomic ions of the analyte is also being done.

Perovskite formation in two step deposition technique occurs via intermixing of the precursors (e.g. MAI and $\mathrm{PbI}_{2}$ for $\mathrm{MAPbI}_{3}$ ) [28]. However, an even distribution is not always observed even in high performing solar cells. Therefore, it would be possible to identify the interface between MAI and $\mathrm{PbI}_{2}$ by the profiles. The intersection of ${ }^{12} \mathrm{C}^{+}\left({ }^{14} \mathrm{~N}^{+}\right)$and ${ }^{204} \mathrm{~Pb}^{+}$ signals in rf-PGD-ToFMS profile (Fig. 2) defines this interface. Signal of $\mathrm{I}\left({ }^{127} \mathrm{I}^{40} \mathrm{Ar}^{+}\right)$is observed throughout the film because of its presence in both MAI and $\mathrm{PbI}_{2}$. The ${ }^{204} \mathrm{~Pb}^{+}$signal has two peaks - one near the glass and the other near the surface of the sample. The peak near the glass is dominating and expected to be due to the $\mathrm{PbI}_{2}$ [29]. The peak near the surface of the sample can be related to intermixing of incomplete $\mathrm{PbI}_{2}$ into MAI which is the basic process as quoted earlier.

Concerning the $\mathrm{MAPbCl}_{2} \mathrm{I}$ samples where $\mathrm{PbCl}_{2}$ was employed as precursor, it was not possible to detect $\mathrm{Cl}$ signal in the mass spectra. In general, the analysis of halogens are challenging by GD sources due to their relatively high excitation levels and ionization potentials. $\mathrm{Cl}$ is particularly difficult because its ionization potential is well above the energy of the $\mathrm{Ar}$ metastable level $(12.96 \mathrm{eV} \mathrm{Cl}$ ionization potential versus $11.6 \mathrm{eV}$ Ar metastable energy) which is the primary reason for ionization processes in the afterglow region. Thus, although $\mathrm{Cl}$ was not monitored in the analysis of $\mathrm{MAPbCl}_{2} \mathrm{I}$ samples, depth profiles of other sample constituents are shown for comparison between the different perovskite films investigated. 


\subsection{Depth profile analysis of perovskite films using different precursors and}

preparation procedures.

Table 1 collects the solvents employed for perovskite layer formation. DMF was used as the organic solvent in the preparation of $\mathrm{MAPbI}_{3}$ and $\mathrm{MAPbBr}_{2} \mathrm{I}$ samples, whereas DMSO was used for $\mathrm{MAPbCl}_{2} \mathrm{I}$ samples. The difference in the organic solvent employed can be detected in rf-PGD-ToFMS profiles by considering the ${ }^{32} \mathrm{~S}^{+}$signal (from DMSO). Whereas no signal was detected for ${ }^{32} \mathrm{~S}^{+}$in $\mathrm{MAPbI}_{3}$ and $\mathrm{MAPbBr}_{2} \mathrm{I}$ samples, Figure 3 collects the depth profiles obtained for ${ }^{32} \mathrm{~S}^{+}$and ${ }^{204} \mathrm{~Pb}^{+}$in $\mathrm{MAPbCl}_{2} \mathrm{I}$, both using method $\mathrm{A}$ and $\mathrm{B}$ for the preparation of perovskite films (Figures $3 \mathrm{a}$ and $3 \mathrm{~b}$, respectively). As expected, a thinner coating layer is observed in the case of $\mathrm{MAPbCl}_{2} \mathrm{I}$ sample prepared with method A (Figure 3a). Moreover, ${ }^{204} \mathrm{~Pb}^{+}$signal suggests a more homogeneous $\mathrm{Pb}$ distribution when lower spin speed was used (Figure 3b) indicating better perovskite crystal formation. Similar to the case of $\mathrm{MAPbI}_{3}$, the signal from $\mathrm{Pb}$ near the surface can be explained due to intermixing of precursors. Although DMSO was used to dissolve the $\mathrm{PbCl}_{2}$ precursor and, therefore, ${ }^{32} \mathrm{~S}^{+}$and ${ }^{204} \mathrm{~Pb}^{+}$signals should exhibit similar depth profiles, experimental results showed a clear diffusion of ${ }^{32} \mathrm{~S}^{+}$to the sample surface in both cases. This provides evidence that DMSO content is left in the perovskite film after the annealing step. In the two-step approach, $\mathrm{PbCl}_{2}$ is first deposited from DMSO and then annealed. As DMSO possesses a relatively high boiling point $\left(189^{\circ} \mathrm{C}\right)$, it can be concluded that the annealing does not remove the complete amount of the solvent [30]. The residual solvent generally diffuses through the film towards the top, as evidenced by the ${ }^{32} \mathrm{~S}^{+}$signal at the sample surface in $\mathrm{MAPbCl}_{2} \mathrm{I}$. This uneven distribution of solvent can be due to the direction of illumination during ageing; as light is incident from the bottom surface, solvents evaporate towards the top layer and, thus, the ${ }^{32} \mathrm{~S}^{+}$signal is lowest at the bottom surface.

Figure 4 shows the elemental depth profile obtained for $\mathrm{MAPbBr}_{2} \mathrm{I}$ sample (method B) by rf-PGD-ToFMS. A good depth resolution is observed in the profile for the coating layers, distinguishing a non-homogeneous distribution of the perovskite film deposited on the glass substrate. Although $\mathrm{Pb}$ and $\mathrm{Br}$ were deposited together in the form of $\mathrm{PbBr}_{2}$ precursor, clearly a different profile was exhibited by ${ }^{204} \mathrm{~Pb}^{+}$and ${ }^{79} \mathrm{Br}^{40} \mathrm{Ar}^{+}$, suggesting an enrichment of $\mathrm{PbBr}_{2}$ at the film surface. This enrichment of ${ }^{79} \mathrm{Br}^{40} \mathrm{Ar}^{+}$was easily identified at the first seconds of the analysis, matching with the first maximum of ${ }^{127} \mathrm{I}^{40} \mathrm{Ar}^{+}$(from MAI). This enrichment can be a result of intermixing of precursors in two step process as discussed earlier. On the other hand, it should be stated that the low signal of ${ }^{127} \mathrm{I}^{40} \mathrm{Ar}^{+}$observed at the glass substrate can be 
attributed to the mentioned memory effect of iodide and no to a real presence of iodide in the glass.

In order to demonstrate the potential of rf-PGD-ToFMS for evaluating different perovskite films preparation techniques, Figure 5 shows depth profiles of ${ }^{127} \mathrm{I}^{40} \mathrm{Ar}^{+}$and ${ }^{204} \mathrm{~Pb}^{+}$ for the three precursors employed: $\mathrm{MAPbI}_{3}\left(\mathrm{PbI}_{2}\right), \mathrm{MAPbCl}_{2} \mathrm{I}\left(\mathrm{PbCl}_{2}\right)$, and $\mathrm{MAPbBr}_{2} \mathrm{I}\left(\mathrm{PbBr}_{2}\right)$ samples. As can be observed, it was possible to obtain the depth distribution of the analytes in less than $30 \mathrm{~s}$, showing a non-homogeneous and a different elemental distribution in all cases. As it should be expected, ${ }^{127} \mathrm{I}^{40} \mathrm{Ar}^{+}$presents a higher content and a wider thickness in $\mathrm{MAPbI}_{3}$ sample compared to $\mathrm{MAPbCl}_{2} \mathrm{I}$ and $\mathrm{MAPbBr}_{2} \mathrm{I}$, because $\mathrm{I}$ content is higher in this case (Figure 5a). On the other hand, a narrower distribution of ${ }^{127} \mathrm{I}^{40} \mathrm{Ar}^{+}$was observed for $\mathrm{MAPbCl}_{2} \mathrm{I}$ in comparison to the $\mathrm{MAPbBr}_{2} \mathrm{I}$. It should also be noted that the ${ }^{127} \mathrm{I}^{40} \mathrm{Ar}^{+}$signal is prominent near the surface due to MAI. In all cases, background signal of ${ }^{127} \mathrm{I}^{40} \mathrm{Ar}^{+}$reached a constant value in the glass substrate after $30 \mathrm{~s}$.

Concerning $\mathrm{Pb}$, although similar profiles are expected for ${ }^{204} \mathrm{~Pb}^{+}$in the three samples, a narrower distribution of ${ }^{204} \mathrm{~Pb}^{+}$can be clearly distinguished for $\mathrm{MAPbCl}_{2} \mathrm{I}$ (Figure 5b). In case of $\mathrm{MAPbI}_{3}$ and $\mathrm{MAPbBr}_{2} \mathrm{I},{ }^{204} \mathrm{~Pb}^{+}$signal is maximum near the glass substrate but it is also observed throughout the film. The maximum of the signal near the glass substrate is due to $\mathrm{PbI}_{2}$ as found in fresh sample. However, rf-PGD-ToFMS profiles do not allow us to differentiate between $\mathrm{Pb}$ and compounds of $\mathrm{Pb}$ and, therefore, the material near the glass surface cannot be unambiguously identified as $\mathrm{PbI}_{2}$ or $\mathrm{Pb}$. The peak close to the top of the surface can be attributed to the uneven intermixing of precursors as explained earlier. The profile, in case of $\mathrm{MAPbCl}_{2} \mathrm{I}$, is different from other two perovskites. In this case, the ${ }^{204} \mathrm{~Pb}^{+}$ signal has narrow distribution in comparison to other samples. The film thicknesses were measured by Dektak surface profilometry (averaged 10 times). The $\mathrm{MAPbBr}_{2} \mathrm{I}$ was measured at $375 \mathrm{~nm}$, the $\mathrm{MAPbI}_{3}$ films at $365 \mathrm{~nm}$ whereas the $\mathrm{MAPbCl}_{2} \mathrm{I}$ film was measured at $290 \mathrm{~nm}$. The $\mathrm{Pb}$ distribution is dependent on the thickness of the sample resulting in a broad profile of $\mathrm{MAPbBr}_{2} \mathrm{I}$ and the $\mathrm{MAPbBr}_{2} \mathrm{I}$ and a narrower profile for $\mathrm{MAPbCl}_{2} \mathrm{I}$. We have also mentioned that the perovskite decomposes into MAI and $\mathrm{PbX}\left(\mathrm{PbCl}_{2}\right.$ in case of $\left.\mathrm{MAPbCl}_{2} \mathrm{I}\right)$ which can further induce $\mathrm{PbCl}^{-}$ions. These ions can be difficult to detect due to the presence of $\mathrm{Cl}^{-}$as discussed in section 3.1 observed in previous TOFSIMS studies [15]. This detection limitation can also result in the narrowing of $\mathrm{Pb}$ distribution.

Conversely, differences of the elemental depth profiles of fresh and aged samples were observed. As an example, Figure 6 shows ${ }^{204} \mathrm{~Pb}^{+}$profiles obtained for $\mathrm{MAPbI}_{3}$ and $\mathrm{MAPbCl}_{2} \mathrm{I}$ for the two sets of samples: fresh and aged. In both cases, the ${ }^{204} \mathrm{~Pb}^{+}$signal is showing a 
maximum near the glass surface for fresh sample indicating towards non-reacted $\mathrm{PbI}_{2}$. However, as the samples were aged, we observed a broadening of the signal. This could be attributed to the decomposition of perovskite into MAI and $\mathrm{PbX}(\mathrm{X}$ is halide) and then lead halide further suffers a decomposition [31-33]. In case of $\mathrm{MAPbCl}_{2} \mathrm{I}$, the profile of ${ }^{204} \mathrm{~Pb}^{+}$ shows a different distribution after degradation. The signal is narrow and centered near the top of the surface.

\subsection{Study of the elemental distribution variation in perovskite films with time.}

As explained in the experimental section, to prevent any immediate degradation of the perovskite films, samples were encapsulated and stored in the dark and inside a desiccator before rf-PGD-ToFMS analysis. Depth profiles obtained from such samples showed the high sensitivity of rf-PGD-ToFMS for detecting small changes in the samples, regarding precursors $\left(\mathrm{MAPbI}_{3}, \mathrm{MAPbCl}_{2} \mathrm{I}\right.$ and $\mathrm{MAPbBr}_{2} \mathrm{I}$ samples) as well as the preparation strategy employed (methods A and B, for fresh and aged samples). Additionally, to evaluate further degradation processes on perovskites films, the samples were exposed to ambient conditions for one month after the first analysis by rf-PGD-ToFMS: the samples were stored at room temperature and exposed to ambient levels of moisture and light. Figure 7 shows the depth profiles of ${ }^{127} \mathrm{I}^{40} \mathrm{Ar}^{+}$(Figure 7a) and ${ }^{79} \mathrm{Br}^{40} \mathrm{Ar}^{+}$(Figure $7 \mathrm{~b}$ ) obtained from the analysis of $\mathrm{MAPbBr}_{2} \mathrm{I}$ sample. Profiles of the sample obtained just after removing the glass cover are denoted as $t_{0}$ in the graphs. In contrast, profiles obtained for the same sample after one month exposure to ambient conditions are denoted as $t_{30 \text { days. }}$. As observed in the two images (Figure $7 \mathrm{c}$ ), the colour of the perovskite film changed in the period of one month, from a dark orange colour to a clear orange that suggests some change in the sample. Although similar profiles were observed for ${ }^{204} \mathrm{~Pb}^{+}$signal at the two analysis times, different depth profiles of ${ }^{127} \mathrm{I}^{40} \mathrm{Ar}^{+}$ and ${ }^{79} \mathrm{Br}^{40} \mathrm{Ar}^{+}$were clearly seen for $\mathrm{t}_{0}$ and $\mathrm{t}_{30 \text { days }}$ analyses, being the distribution of $\mathrm{I}$ and $\mathrm{Br}$ broader after the sample exposure to moisture and light. However, complementary experiments should be done to better understand what type of processes produce such elemental variations in the samples. The exposure to moisture and oxygen decomposes the perovskite into its constituent materials, i.e. $\mathrm{MAPbI}_{3}$ decomposes into MAI and $\mathrm{PbI}_{2}$ [31]. It has also been reported that $\mathrm{PbI}_{2}$ can further decompose into $\mathrm{Pb}$ and I [32]. On the other hand, photoexcited electrons in the perovskite react with oxygen and form $\mathrm{O}_{2}{ }^{-}$. This $\mathrm{O}_{2}{ }^{-}$is highly reactive to the organic part of perovskite and as a result of this reaction organic cation migrates from the perovskite. Due to exposure to oxygen, perovskite decomposes into its constituent ions which have been observed by using X-ray diffraction spectroscopy [33]. 
Therefore, the rf-PGD-ToFMS data support previous studies which indicate exposure to moisture and oxygen initiates the perovskite film decomposition to constituent ions, which would eventually lead fully decomposed films.

\section{CONCLUSIONS}

Depth profiling analysis of perovskite absorber layers using different synthesis precursors $\left(\mathrm{PbI}_{2}, \mathrm{PbCl}_{2}\right.$ and $\left.\mathrm{PbBr}_{2}\right)$ have been evaluated by rf-PGD-TOFMS for the first time. Experimental results have shown that this analytical tool should be considered more widely by the perovskite solar cell community to characterize the halogen distribution in the coating layers as well as to identify the presence of different degradation and/or diffusion processes in the samples. Furthermore, the high sensitivity of rf-PGD-ToFMS allows identifying an important iodine memory effect for the analysis of perovskite films. Such effect can be corrected by the analysis of a high purity silicon wafer after the analysis of the samples. Due to the high content of such precursors and to avoid saturation with major components, halogen signals were successfully evaluated throughout their polyatomic ions with Ar (e.g. ${ }^{127} \mathrm{I}^{40} \mathrm{Ar}^{+}$and $\left.{ }^{79} \mathrm{Br}^{40} \mathrm{Ar}^{+}\right)$.

Despite the promising performances of PSCs, their poor stability is currently the main obstacle to be overcome. UV light, moisture, oxygen and elevated temperatures have been reported to have a direct influence on PSCs stability. Thus, a preliminary test (exposing the samples to room temperature conditions and light) was performed with perovskite films to evaluate rf-PGD-ToFMS potential to study changes in depth profiles after sample degradation. Depth profiles obtained from samples just after removing the encapsulation cover and one month after exposure to ambient conditions suggest differences in the sample constituents' distribution. A systematic study under different degradation conditions should further develop to understand the degradation mechanisms and their effect on the device performance.

GD-MS is a well-established and mature technique that has been successfully employed for the analysis of a wide variety of materials. Depth resolution in the low nanometers range as well as limits of detection in the ppm-ppb level can be easily obtained with this solid-sate spectrometry technique. It should be finally stated that although qualitative depth profiles (intensity versus analysis time) provide valuable information about coating's layers in perovskite films, information about elemental concentrations can be only extracted after the corresponding calibration procedure. Nevertheless, this is not a straightforward step for PSCs due to the complex nature of the samples and the lack of standards for some of the elements 
present in perovskite films. Further experiments will be devoted to investigate quantitative strategies for the analysis of perovskite films as well as to the analysis of complete solar cell devices (i.e. including back and front contacts).

\section{ACKNOWLEDGEMENTS}

Financial support from Horiba Scientific through a research project is gratefully acknowledged. Also, B.F. acknowledges her research contract RYC-2014-14985 to the Spanish Ministry of Economy and Competitiveness through the Ramón y Cajal Program. Authors thank Samuel Gonzalez for his help during the first PGD-ToFMS optimizations. J.K., P.T. and V.S. would like to acknowledge the European Regional Development Fund (ERDF) and the Welsh European Funding Office (WEFO) for funding the 2nd Solar Photovoltaic Academic Research Consortium (SPARCII) which supported this research and the Sêr Cymru National Research Network. 


\section{REFERENCES}

[1] M. Ragoussia, T. Torres, New generation solar cells: concepts, trends and perspectives, Chem. Commun., 51 (2015) 3957-3972.

[2] G. Peng, X. Xu, G. Xu, Hybrid organic-inorganic perovskites open a new era for low-cost, high efficiency solar cells, J. Nanomaterials, Volume 2015, Article ID 241853, 10 pages.

[3] A. Kojima, K. Teshima, Y. Shirai, T. Miyasaka, Organometal halide perovskites as visible-light sensitizers for photovoltaic cells. J. Am. Chem. Soc.,131 (2009) 6050-6051.

[4] S.S. Shin, E.J. Yeom, W.S. Yang, S. Hur, M.G. Kim, J. Im, J. Seo, J.H. Noh, S.I. Seok, Colloidally prepared La-doped BaSnO3 electrodes for efficient, photostable perovskite solar cells, Science, 356(2017)167-171.

[5] N.-G. Park, Perovskite solar cells: an emerging photovoltaic technology, Materials Today, 18 (2015) 65-72.

[6] M.K. Assadi, S. Bakhoda, R. Saidur, H. Hanaei, Recent progress in perovskite solar cells, Renewable and Sustainable Energy Reviews, 81 (2018) 2812-2822.

[7] G. Niu, X. Guo, L. Wang, Review of recent progress in chemical stability of perovskite solar cells, J. Mater. Chem. A, 3 (2015) 8970-8980.

[8] D. Wang, M. Wright, N.K. Elumalai,A. Uddin, Stability of perovskite solar cells, Solar Energy Materials \& Solar Cells, 147 (2016) 255-275.

[9] M.I. Asghar, J. Zhang, H. Wang, P.D. Lunda, Device stability of perovskite solar cells - A review, Renewable and Sustainable Energy Reviews, 77 (2017) 131-146.

[10] P. Docampo, T. Bein, A long-term view on perovskite optoelectronics, Acc. Chem. Res., 49 (2016) 339-346.

[11] D. Bryant, N. Aristidou, S. Pont, I. Sanchez-Molina,T. Chotchunangatchaval, S. Wheeler, J.R. Durrant, S.A. Haque, Light and oxygen induced degradation limits the operational stability of methylammonium lead triiodide perovskite solar cells, Energy Environ. Sci., 9 (2016) 1655-1660.

[12] J.A. Christians, P.A. Miranda Herrera, P.V. Kamat, Transformation of the excited state and photovoltaic efficiency ofCH3NH3PbI3perovskite upon controlled exposure to humidified air, J. Am. Chem. Soc., 137 (2015) 1530-1538.

[13] J.S. Shaikh, N.S. Shaikh, A.D. Sheikh, S.S. Mali, A.J. Kale, P. Kanjanaboos, C. Kook Hong, J.H. Kime, P.S. Patil, Perovskite solar cells: In pursuit of efficiency and stability, Materials and Design 136 (2017) 54-80.

[14] V. Stoichkov, N Bristow, J. Troughton, F. De Rossi, T.M. Watson, J. Kettle, Outdoor performance monitoring of perovskite solar cell mini-modules: Diurnal performance, observance of reversible degradation and variation with climatic performance, Solar Energy 170 (2018) 549-556. 
[15] F. Matteocci, Y. Busby, J-J. Pireaux, G. Divitini, S. Cacovich,C. Ducati, A. Di Carlo, Interface and composition analysis on perovskite solar cells, ACS Appl. Mater. Interfaces, 7 (2015) 2617626183

[16] H-S. Ko, J-W. Lee, N-G. Park, $15.76 \%$ efficiency perovskite solar cells prepared under high relative humidity: importance of PbI2 morphology in two-step deposition of $\mathrm{CH} 3 \mathrm{NH} 3 \mathrm{PbI} 3$, J. Mater. Chem. A, 3 (2015) 8808-8815.

[17] Y. Busby, A. Agresti, S. Pescetelli, A. Di Carlo, C. Noel, J-J. Pireaux, L. Houssiau, Aging effects in interface-engineered perovskite solar cells with 2Dnanomaterials: A depth profile analysis, Materials Today Energy, 9 (2018) 1-10.

[18] M.A. Barreiros, L.C. Alves, M.J. Brites, V. Corregidor, Depth profile by Total IBA in perovskite active layers for solar cells, Nuclear Instruments and Methods in Physics Research B, 404 (2017) 211218.

[19] Z. Ahmad, M.A. Najeeb, R.A. Shakoor, A. Alashraf, S.A. Al-Muhtaseb, A. Soliman, M.K. Nazeeruddin, Instability in $\mathrm{CH} 3 \mathrm{NH} 3 \mathrm{PbI} 3$ perovskite solar cells due to elemental migration and chemical composition changes, Scientific Reports, 7 (2017) 15406.

[20] L. Lobo, B. Fernandez, R. Pereiro, Depth profile analysis with glow discharge spectrometry, J. Anal. At. Spectrom., 32 (2017) 920-930.

[21] L. Cojocaru, S. Uchida, D. Matsubara, H. Matsumoto, K. Ito, Y. Otsu,P. Chapon, J. Nakazaki, T. Kubo, H. Segawa, Direct confirmation of distribution for $\mathrm{Cl}$ - in $\mathrm{CH} 3 \mathrm{NH} 3 \mathrm{PbI} 3-\mathrm{xClx}$ layer of perovskite solar cells, Chem. Lett., 45 (2016) 884-886.

[22] H. Lee, S. Gaiaschi, P. Chapon, A. Marronnier, H. Lee, J-C. Vanel, D. Tondelier, J-E. Bourée, Y. Bonnassieux, B. Geffroy, Direct experimental evidence of halide ionicmigration under bias in $\mathrm{CH}_{3} \mathrm{NH}_{3} \mathrm{PbI}_{3-\mathrm{x}} \mathrm{Cl}_{\mathrm{x}}$ based perovskite solar cells using GD-OES analysis, ACS Energy Lett., 2 (2017) 943-949.

[23] D.W. de Quilettes, S. Koch, S. Burke, R.K. Paranji, A.J. Shropshire, M.E. Ziffer,D.S. Ginger, Photoluminescence lifetimes exceeding $8 \mu$ s and quantum yields exceeding 30\% in hybrid perovskite thin films by ligand passivation, ACS Energy Lett., 1 (2016) 438-444.

[24] C. González-Gago, N. Nordel, R. Pereiro, A. Sanz-Medel, Investigation of theafterglow time regime in pulsed radiofrequency glow discharge time-of-flight mass spectrometry, J. Mass Spectrom., 46 (2011) 757-763.

[25] B. Fernandez, L. Lobo, N. Reininghaus, R. Pereiro, A. Sanz-Medel, Characterization of thin film tandem solar cells by radiofrequency pulsed glow discharge - Time of flight mass spectrometry, Talanta, 165 (2017) 289-296.

[26] A. Al-Ammar, E. Reitznerová, R.M. Barnes, Thorium and iodine memory effects in inductivelycoupled plasma mass spectrometry, Fresenius J. Anal. Chem., 370 (2001) 479-482. 
[27] Y.-C. Zhao, W.-K. Zhou, X. Zhou, K.-H. Liu, D.-P. Yu, Q. Zhao, Quantification of lightenhanced ionic transport in lead iodide perovskite thin films and its solar cell applications, Light: Science \& Applications 6 (2017), e16243

[28] J. Burschka, N. Pellet, S. J. Moon, R. Humphry-Baker, P. Gao, M. K. Nazeeruddin, M. Gratzel, Sequential deposition as a route to high-performance perovskite-sensitized solar cells, Nature 499 (2013) 316-319.

[29] A. A. Melvin, V. Dimitrov Stoichkov, J. Kettle, D. Mogilyansky, E.A. Katz, I. Visoly-Fisher, Lead iodide as a buffer layer in UV-induced degradation of $\mathrm{CH}_{3} \mathrm{NH}_{3} \mathrm{PbI}_{3}$ Films, Solar Energy 159 (2018) 794-799.

[30] X. Li, D. Bi, C. Yi, J.-D. Décoppet, J. Luo, S. M. Zakeeruddin, A. Hagfeldt, M. Grätzel, A vacuum flash-assisted solution process for high-efficiency large-area perovskite solar cells, Science 353 (2016) 58-62.

[31] Z. Song, A. Abate, S.C. Watthage, G.K. Liyanage, A.B. Phillips, U. Steiner, M. Graetzel, M J. Heben, In-situ observation of moisture-induced degradation of perovskite solar cells using laser-beam induced current, Photovoltaic Specialists Conference (PVSC), 2016, 1202-1206.

[32] E. J. Juarez-Perez, L.K. Ono, M. Maeda, Y. Jiang, Z. Hawasha, Y. Qi, Photodecomposition and thermal decomposition in methylammonium halide lead perovskites and inferred design principles to increase photovoltaic device stability, J. Mater. Chem. A, 6 (2018) 9604-9612.

[33] N. Aristidou, I. Sanchez-Molina, T. Chotchuangchutchaval, M. Brown, L. Martinez, T. Rath, S. A. Haque, The role of oxygen in the degradation of methylammonium lead trihalide perovskite photoactive layers, Angew. Chem. 54 (2015) 8208-8212. 
Table 1. Perovskite precursors and conditions employed for the samples studied in this work.

\begin{tabular}{|c|c|c|c|}
\hline Sample & $\begin{array}{c}\text { Perovskite Precursor }(\& \\
\text { solvent })\end{array}$ & Method "A" & Method "B" \\
\hline $\begin{array}{l}\mathbf{M A P b I}_{3} \\
\left(\mathrm{CH}_{3} \mathrm{NH}_{3} \mathrm{PbI}_{3}\right)\end{array}$ & $\begin{array}{l}\mathrm{PbI}_{2}(461 \mathrm{mg} / \mathrm{mL})-\mathrm{DMF} \\
\text { MAI }(30 \mathrm{mg} / \mathrm{mL})-\mathrm{IPA}\end{array}$ & \multirow[t]{3}{*}{$\begin{array}{c}\mathrm{PbI}_{2} / \mathrm{PbBr}_{2} / \mathrm{PbCl}_{2}: \\
6000 \mathrm{rpm}: 40 \mathrm{~s}\end{array}$} & \multirow[t]{2}{*}{$\begin{array}{c}\mathrm{PbI}_{2} / \mathrm{PbBr}_{2} / \mathrm{PbCl}_{2}: \\
2000 \text { rpm: } 40 \mathrm{~s}\end{array}$} \\
\hline $\begin{array}{l}\mathbf{M A P b B r}_{2} \mathbf{I} \\
\left(\mathrm{CH}_{3} \mathrm{NH}_{3} \mathrm{PbBr}_{2} \mathrm{I}\right)\end{array}$ & $\begin{array}{l}\mathrm{PbBr}_{2}(367 \mathrm{mg} / \mathrm{mL})-\mathrm{DMF} \\
\mathrm{MAI}(30 \mathrm{mg} / \mathrm{mL})-\mathrm{IPA}\end{array}$ & & \\
\hline $\begin{array}{l}\mathbf{M A P b C l} \mathbf{I} \\
\left(\mathrm{CH}_{3} \mathrm{NH}_{3} \mathrm{PbCl}_{2} \mathrm{I}\right)\end{array}$ & $\begin{array}{l}\mathrm{PbCl}_{2}(300 \mathrm{mg} / \mathrm{mL})-\mathrm{DMSO} \\
\text { MAI }(30 \mathrm{mg} / \mathrm{mL})-\mathrm{IPA}\end{array}$ & & $\begin{array}{c}\text { MAI: } \\
6000 \mathrm{rpm}: 40 \mathrm{~s}\end{array}$ \\
\hline
\end{tabular}

Table 2. Integration interval (afterglow region of GD pulse profile) employed for data treatment for the different ions investigated. Experimental conditions used: $70 \mathrm{~W}, 120 \mathrm{~Pa}, 200$ $\mu$ s pulse width, and $1400 \mu$ s pulse period.

\begin{tabular}{|l|c|}
\hline \multicolumn{1}{|c|}{ Ion } & $\begin{array}{c}\text { Time interval (ms) } \\
\text { selected in the GD pulse } \\
\text { profile }\end{array}$ \\
\hline${ }^{12} \mathbf{C}^{+}$ & $0.348-0.481$ \\
\hline${ }^{14} \mathbf{N}^{+}$ & $0.350-0.483$ \\
\hline${ }^{16} \mathbf{O}^{+}$ & $0.532-0.665$ \\
\hline${ }^{24} \mathbf{M g}^{+}$ & $0.602-0.735$ \\
\hline${ }^{28} \mathbf{S i}^{+}$ & $0.554-0.687$ \\
\hline${ }^{32} \mathbf{S}^{+}$ & $0.379-0.426$ \\
\hline${ }^{204} \mathbf{P b}^{+}$ & $0.500-0.633$ \\
\hline${ }^{79} \mathbf{B r}^{40} \mathbf{A r}^{+}$ & $0.455-0.588$ \\
\hline${ }^{127} \mathbf{I}^{40} \mathbf{A r}^{+}$ & $0.545-0.678$ \\
\hline
\end{tabular}




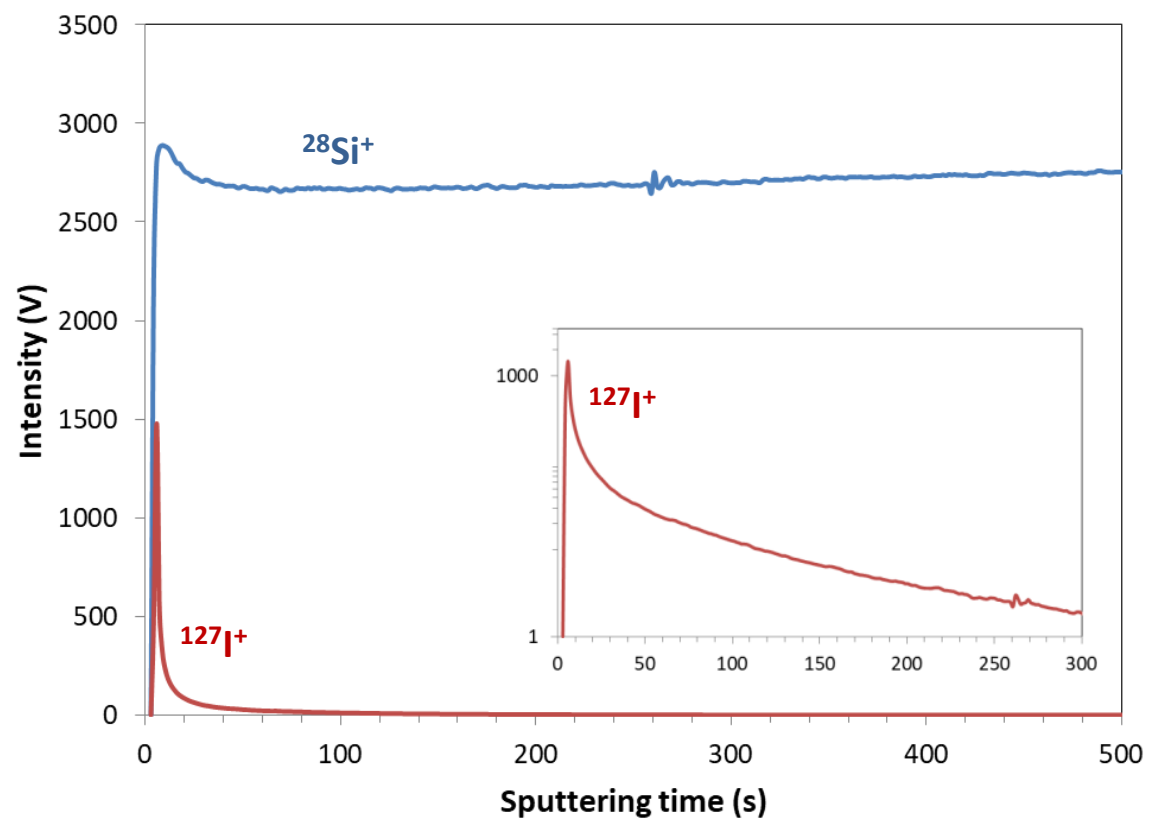

Figure 1. Depth profile analysis of a high-purity silicon wafer by rf-PGD-ToFMS performed just after the analysis of $\mathrm{MAPbI}_{3}$ sample. The expanded graph collects ${ }^{127} \mathrm{I}^{+}$signal for the first $5 \mathrm{~min}$ of the analysis in a logarithmic scale. 


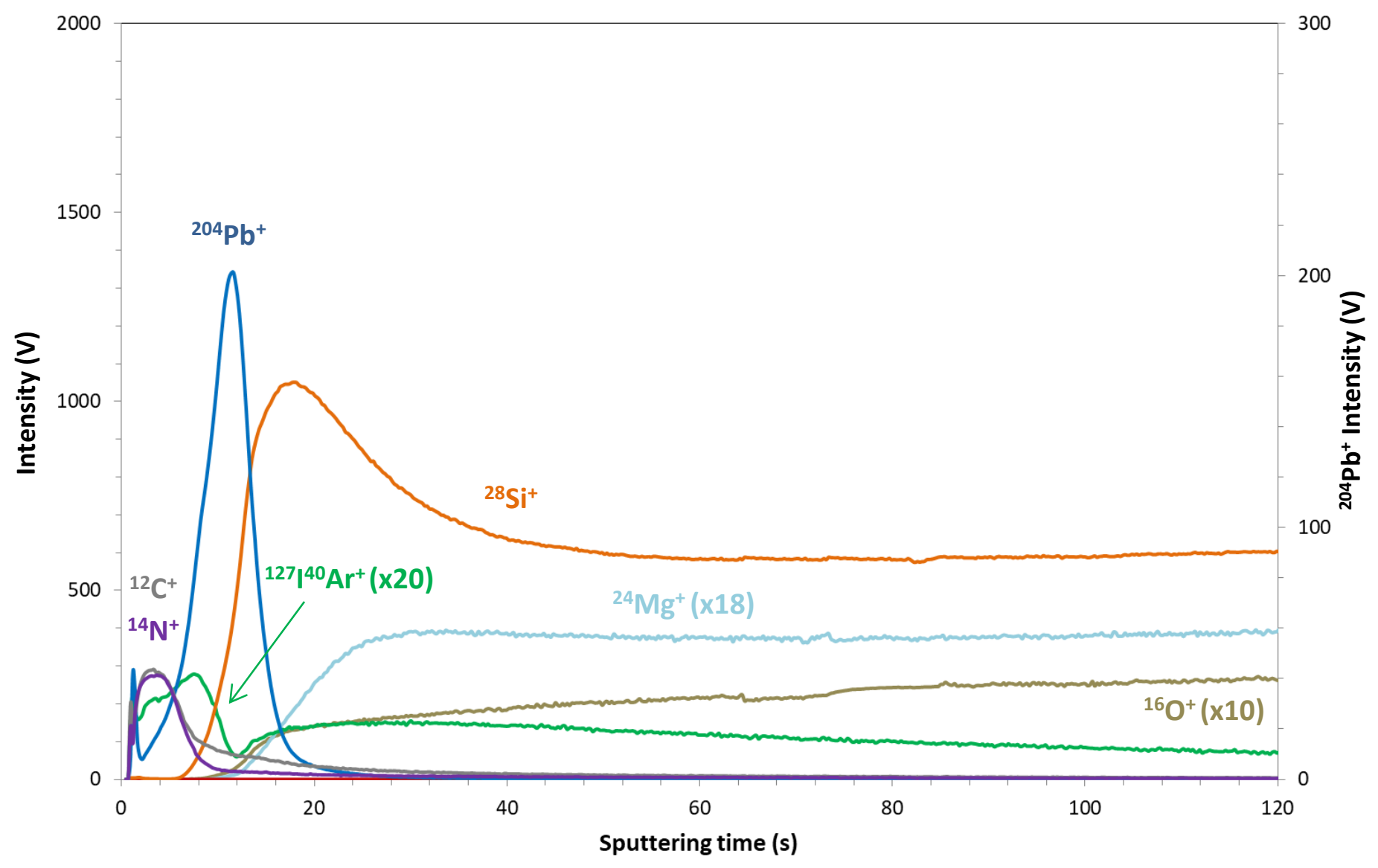

Figure 2. Depth profile analysis of $\mathrm{MAPbI}_{3}$ sample (method A and fresh) by rf-PGD-ToFMS. 
a)

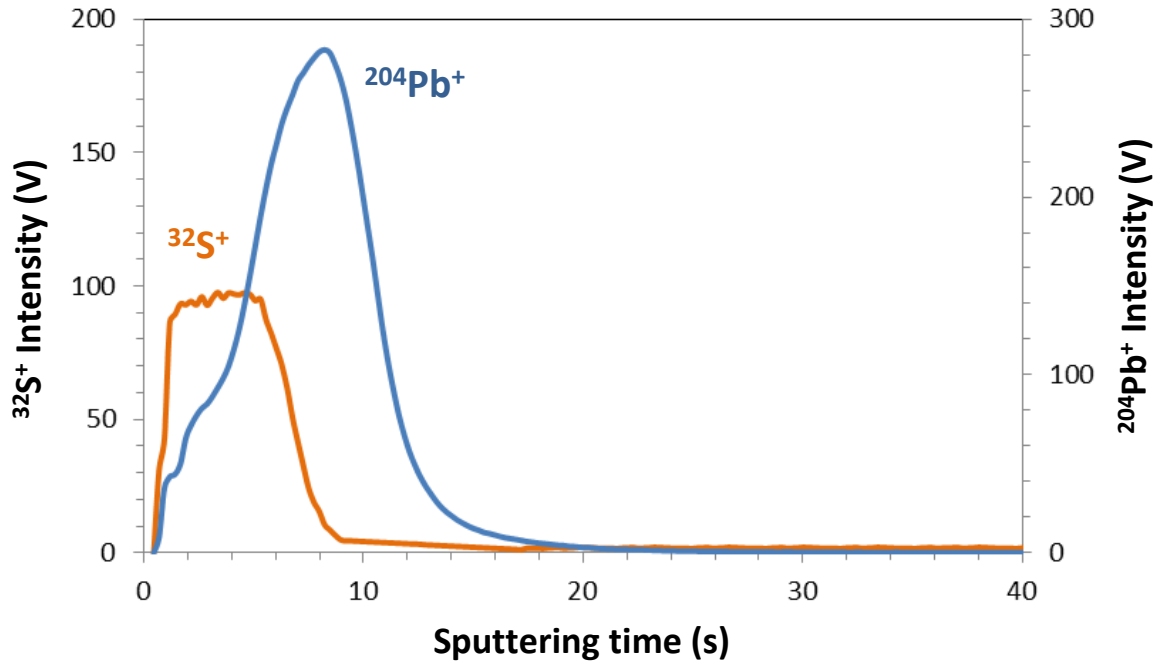

b)

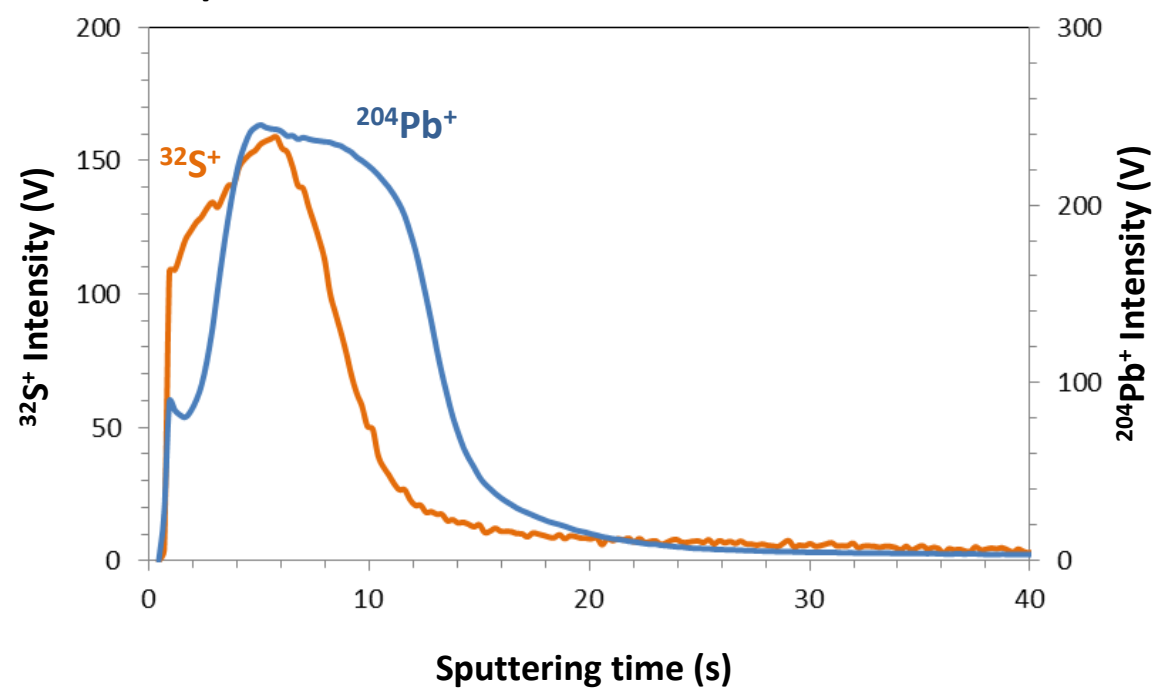

Figure 3. Depth profiles obtained by rf-PGD-ToFMS for ${ }^{32} \mathrm{~S}^{+}$and ${ }^{204} \mathrm{~Pb}^{+}$signals of $\mathrm{MAPbCl}_{2} \mathrm{I}$ samples using the two preparation methods (aged samples exposed to a solar simulator ). a) Method A, and b) Method B. 


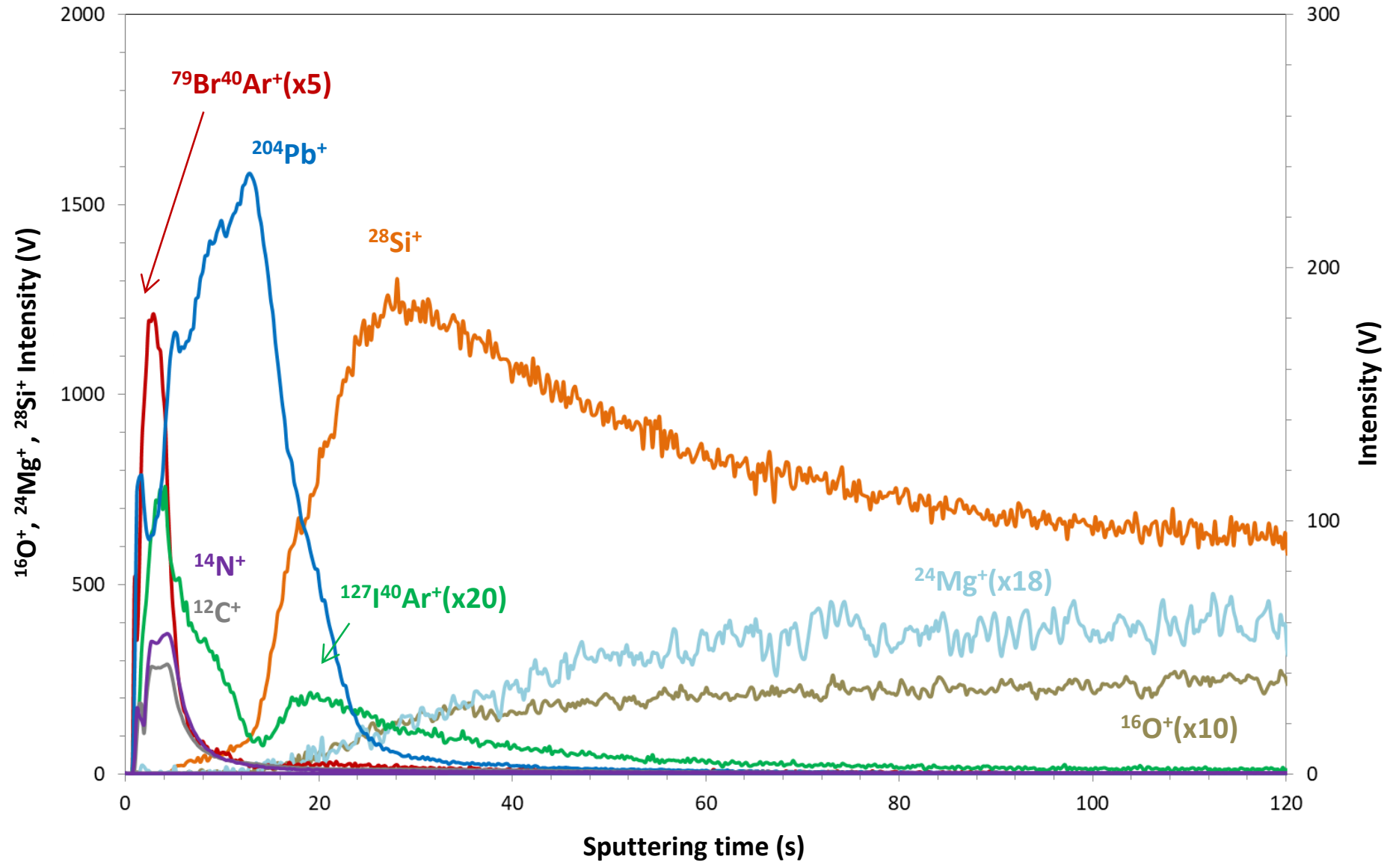

Figure 4. Depth profile analysis of $\mathrm{MAPbBr}_{2} \mathrm{I}$ sample (method B and aged) by rf-PGD-ToFMS. 
a)

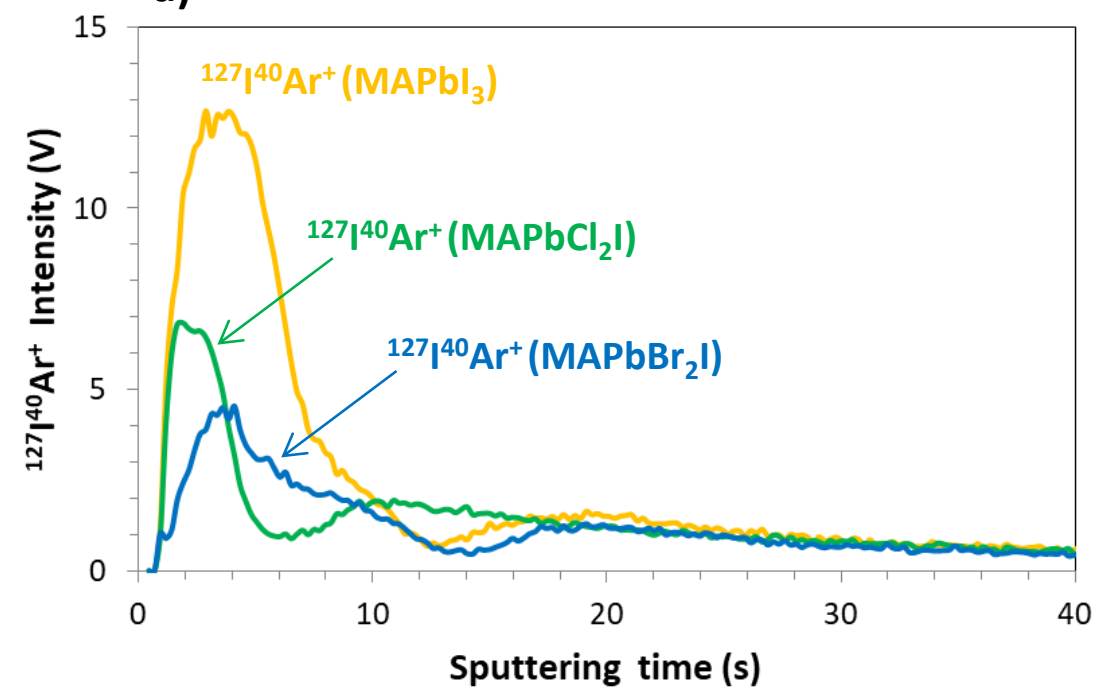

b)

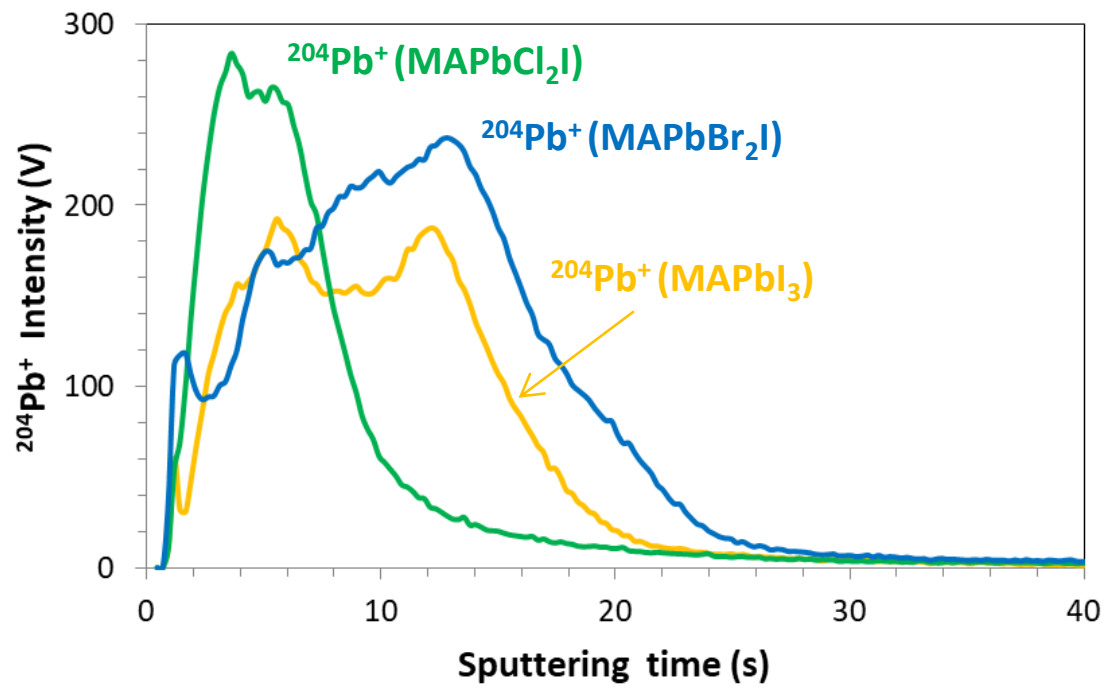

Figure 5. Depth profiles obtained for the analysis of $\mathrm{MAPbI}_{3}, \mathrm{MAPBr}_{2} \mathrm{I}$, and $\mathrm{MAPbCl}_{2} \mathrm{I}$ samples (aged samples exposed to a solar simulator) by rf-PGD-ToFMS. a) ${ }^{127} \mathrm{I}^{40} \mathrm{Ar}^{+}$signal, and b) ${ }^{204} \mathrm{~Pb}^{+}$signal. 
a)

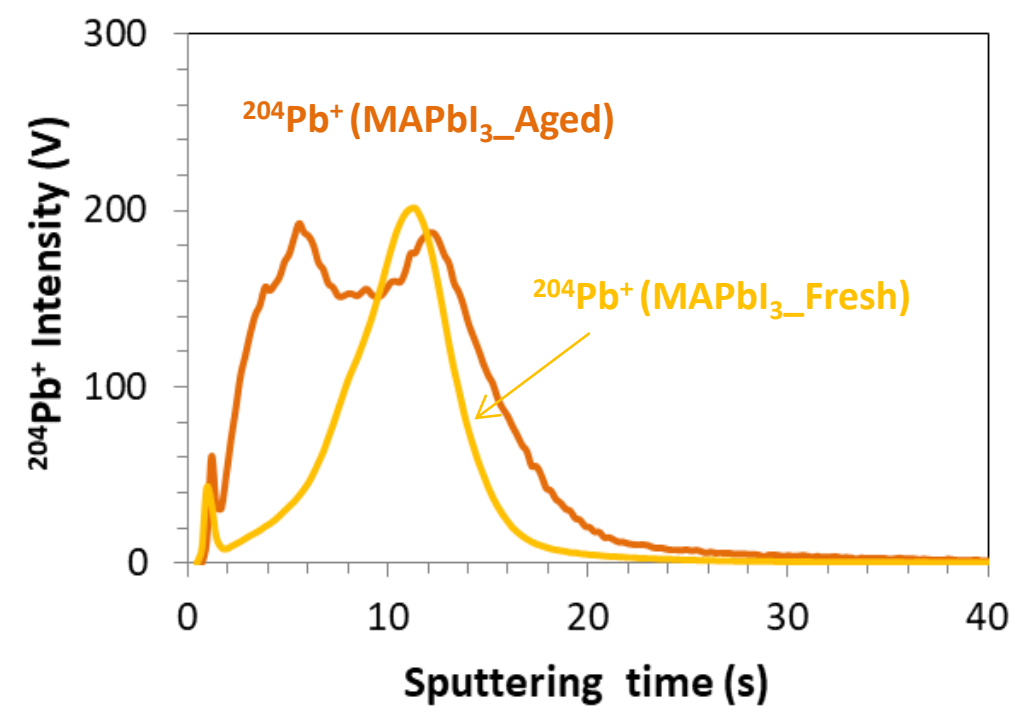

b)

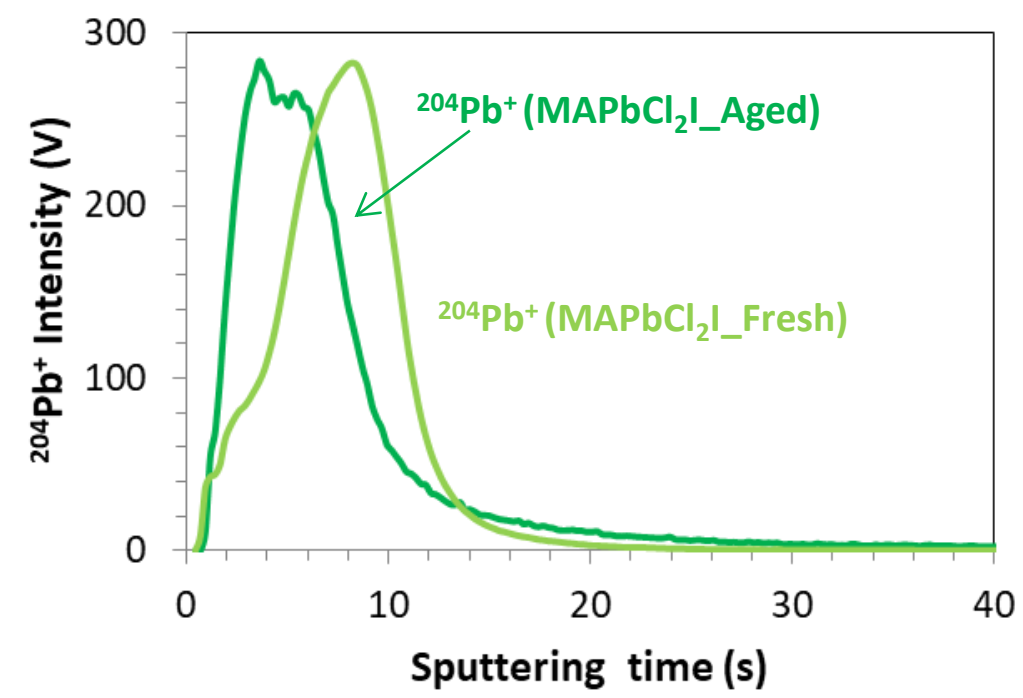

Figure 6. ${ }^{204} \mathrm{~Pb}^{+}$depth profiles obtained for the analysis of $\mathrm{MAPbI}_{3}$ and $\mathrm{MAPbCl}_{2} \mathrm{I}$ for the two set of samples: fresh and aged. a) ${ }^{204} \mathrm{~Pb}^{+}$signal for $\mathrm{MAPbI}_{3}$ samples, and b) ${ }^{204} \mathrm{~Pb}^{+}$signal for $\mathrm{MAPbCl}_{2} \mathrm{I}$ samples. 
a)
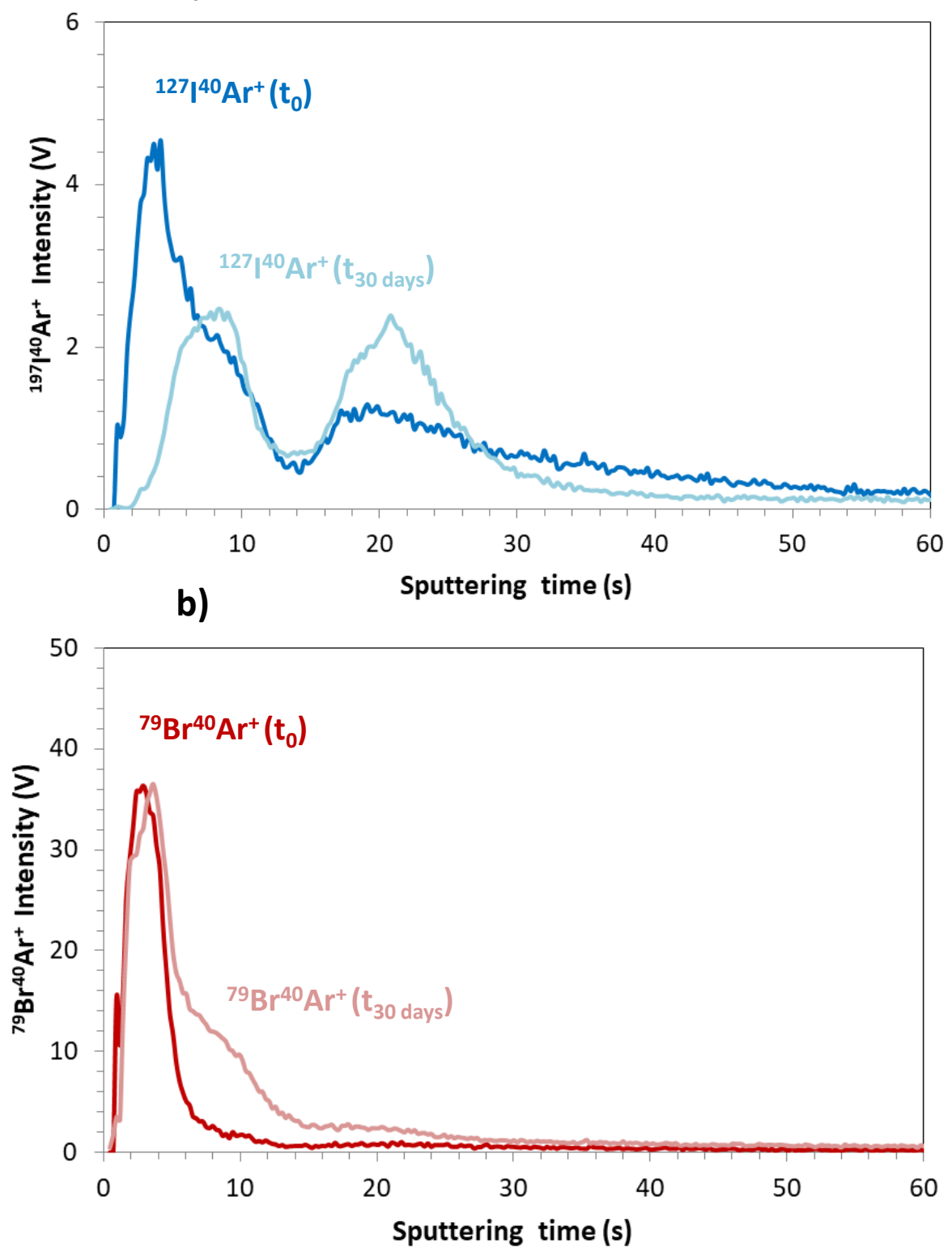

c)
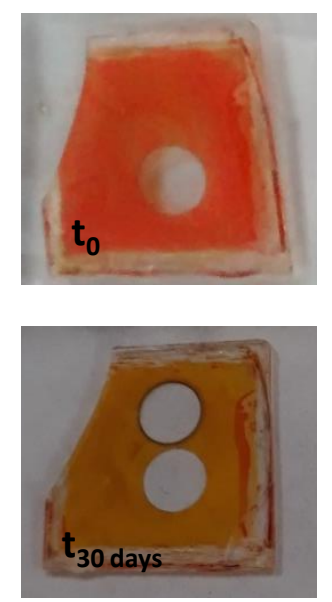

Figure 7. Depth profiles obtained for $\mathrm{MAPbBr}_{2} \mathrm{I}$ sample (method $\mathrm{B}$ and aged) by rf-PGD-ToFMS just after removing the encapsulation $\left(t_{0}\right)$ and one month later $\left(t_{30 \text { days }}\right)$. a) ${ }^{127} \mathrm{I}^{40} \mathrm{Ar}^{+}$signal, b) ${ }^{79} \mathrm{Br}^{40} \mathrm{Ar}^{+}$signal, and c) Pictures of the sample after GD analysis at $t_{0}$ and $t_{30 \text { days }}$. 